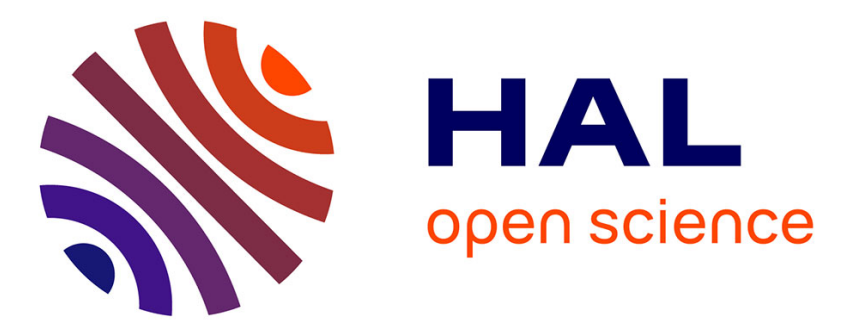

\title{
Levodopa has primarily negative influences on postural control in patients with parkinson's disease
}

Cédrick T. Bonnet, Arnaud Delval, Sébastien Szaffarczyk, Luc Defebvre

\section{To cite this version:}

Cédrick T. Bonnet, Arnaud Delval, Sébastien Szaffarczyk, Luc Defebvre. Levodopa has primarily negative influences on postural control in patients with parkinson's disease. Behavioural Brain Research, 2017, 331, pp.67-75. 10.1016/j.bbr.2017.05.033 . hal-02186152v3

\section{HAL Id: hal-02186152 \\ https://hal.univ-lille.fr/hal-02186152v3}

Submitted on 10 Aug 2021

HAL is a multi-disciplinary open access archive for the deposit and dissemination of scientific research documents, whether they are published or not. The documents may come from teaching and research institutions in France or abroad, or from public or private research centers.
L'archive ouverte pluridisciplinaire HAL, est destinée au dépôt et à la diffusion de documents scientifiques de niveau recherche, publiés ou non, émanant des établissements d'enseignement et de recherche français ou étrangers, des laboratoires publics ou privés. 


\title{
Levodopa has primarily negative influences on postural control in patients with Parkinson's
} disease

Cédrick T. Bonnet ${ }^{1}$, Arnaud Delval ${ }^{2,4}$, Sébastien Szaffarczyk ${ }^{1}$ and Luc Defebvre ${ }^{3,4}$

${ }^{1}$ Univ. Lille, CNRS, UMR 9193 - SCALab - Sciences Cognitives et Sciences Affectives, F59000 Lille, France

${ }^{2}$ Service de neurophysiologie clinique, Hôpital Salengro, CHRU, F-59000 Lille, France

${ }^{3}$ Service de neurologie et pathologie du mouvement, centre expert Parkinson, Hôpital Salengro, CHRU, F-59000 Lille, France

${ }^{4}$ Unité INSERM 1171, Faculté de médecine, Université de Lille, F-59000 Lille, France

Running title: Levodopa's influences on postural control

\begin{abstract}
Patients with Parkinson's disease have better functional status and motor performance under on-drug conditions. However, the administration of levodopa leads to greater postural sway. The present study's primary objective was to determine whether this on-drug problem may be related to a lack of adjustment in postural control mechanisms and body segment rotations. Fourteen patients with Parkinson's disease and 14 controls performed two gaze-shift tasks ( $40^{\circ}$ to the left and $40^{\circ}$ to the right, at 0.125 and $0.25 \mathrm{~Hz}$ ) and a stationary gaze task in two sessions (an off-drug session and an on-drug session for the patients, and two off-drug sessions for the controls). At baseline, the "on-drug" patients indeed swayed significantly more than the controls during the gaze-shift tasks. As expected, acute L-dopa administration did not increase eye, head, neck and lower back rotation of the patients during the gaze-shift tasks. Unexpectedly, levodopa appeared to enable the patients to significantly increase the contribution of their postural control mechanisms (relative to controls) during the gaze-shift tasks. However, and as expected, this adjustment was not great enough to enable the patients to maintain their postural sway as well as the controls did. Overall, the administration of levodopa seemed to destabilize the patients - especially with regard to the lower back region. In addition, the patients used hypermetric eye rotations during the gaze-shift tasks under both off- and on-drug conditions. If they had not used these compensatory eye rotations, their unsafe behavior at the hip level might have been even more pronounced. Future research should focus on this lower back weakness.
\end{abstract}

Keywords: Parkinson's disease; postural control mechanisms; body rotation; body sway; visual tasks; off- and on-drug sessions 


\section{Introduction}

Parkinson's disease (PD) is notably characterized by motor impairments, such as rest tremor, rigidity, slowness of movement, hypokinesia, and (at later stages) postural instability. In stance, patients with late-stage PD (Hoehn and Yahr stage >2.5) are known to fall more often [1] and to have a greater incidence of hip fracture than controls [2]. It is therefore essential for clinicians and patients to better understand, correct and prevent these diseaserelated impairments in postural control; in turn, this should enable patients to interact more safely with their environment and experience a better quality of life.

Administration of antiparkinsonian medication reduces the patient's level of motor disability [3], as evidenced by a lower mean Unified Parkinson's Disease Rating Scale (UPDRS) motor (part III) score [4]. Medication also improves motor task performance, e.g. by increasing the ability to lean forward in the functional reach test [5]. However, it has been shown that on-drug patients with PD sway significantly more than controls in both quiet stance [6-9] and challenging stance conditions [6,10]. This levodopa-associated increase in postural sway is problematic because it may increase the risk of falls in patients with PD especially if the latter suffer from dyskinesia and have already fallen [11]. Hence, it is important to understand why levodopa increases postural sway.

In a recent study [12], on-drug PD-related impairments in mediolateral (ML) postural coordination were assessed by administering various visual tasks. The visual tasks (a single gaze shift to the left or to the right) were intended to challenge the participants' coordination. By means of a principal component analysis, Anastasopoulos et al. [12] showed that in order to fix the target, patients with PD rotated their body less at the trunk and the head (relative to healthy controls) but rotated their eyes more, despite the lack of a physical impairment in body segment coordination. On the same lines, we recently studied PD-related impairments in body sway, segment rotation and postural control mechanisms during an off-drug session [13]. Postural control mechanisms were analyzed as described by Winter et al. $[14,15]$. Briefly, the main mechanism for controlling ML postural sway is the bodyweight distribution mechanism. In order to stabilize ML upright stance, body weight is loaded onto one leg and therefore unloaded from the other leg (Figure 1, left part). The center of pressure (COP) location mechanism is a secondary mechanism performed by inversion/eversion at the ankle (Figure 1, right part; $[14,15]$ ). We used two active gaze-shift tasks to perturb the participants' posture [13]. The patients with PD tracked the visual target mainly by turning their whole body while the controls primarily turned their head. Unlike the controls, the patients with PD did not increase the contributions of their bodyweight and COP location mechanisms in the gaze-shift tasks, relative to the stationary gaze task. This may explain why the patients exhibited significantly greater ML motion (relative to the controls) for the body as a whole and for the lower back in particular. Our previous study did not test for medication-related changes in postural control mechanisms, coordination and body motion in patients with PD [13]. Understanding these aspects is important because the insufficient adjustment of postural control mechanisms and body coordination may explain why patients with PD sway more than controls - especially under on-drug conditions [6-10]. In fact, we had three reasons to hypothesize that levodopa administration would not have any effect on the strength of the postural control mechanisms. Firstly, the literature data suggested that levodopa did not modify control mechanisms or EMG profiles in PD [5,16,17]. Secondly, levodopa did not change the amplitude of the activity of proximal muscle (the rectus femoris, biceps femoris and paraspinal muscles) under quiet stance conditions [7] and was only associated with a partial change in axial rigidity [18]. In contrast, most of the ML postural control occurred at the hips $[14,15]$. Thirdly (and as mentioned above), on-drug patients with PD are known to sway more than controls $[6,16]$, which shows that the control mechanisms are insufficient. 
The present study's primary objective was to characterize the influence of acute levodopa administration on body sway, segment rotation and control mechanisms in patients with PD and in healthy controls. The two groups of participants performed two successive sessions with two gaze-shift tasks $\left(40^{\circ}\right.$ to the left and $40^{\circ}$ to the right, at 0.125 and $\left.0.25 \mathrm{~Hz}\right)$ and a stationary gaze task. The patients performed an off-drug session and then an on-drug session, whereas the controls performed two off-drug sessions. To replicate the data in the literature and as a basis for our main analyses, we expected the patients to sway more under on-drug conditions than under off-drug conditions (hypothesis H1) [10] - particularly at the lower back [13]. If this initial finding was correct, we further hypothesized that levodopa would not improve postural control mechanisms and body segment rotations under gaze-shift conditions (H2 and $\mathrm{H} 3$, the main hypotheses). We therefore expected the patients' sway to be more sensitive to the difficulty of the visual task, relative to controls. However, levodopa was expected to improve the patients' visual task performance (H4) and functional status (H5), as frequently reported in the literature $[3,4]$. The study's secondary objective was to confirm the disease-related (off-drug) effects on body sway, segment rotation and control mechanisms observed in our earlier study [13].

A

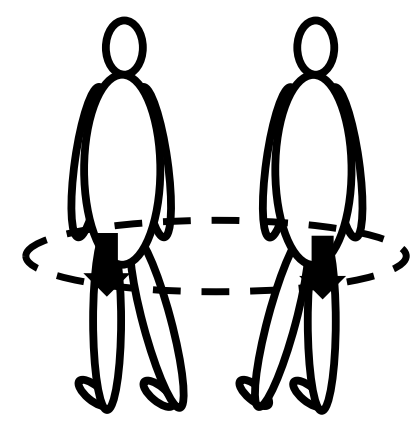

B

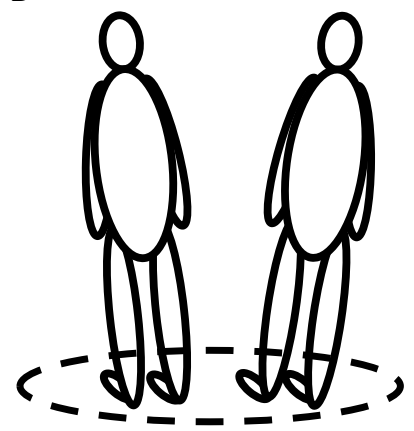

Figure 1. (A) Graphical representation of the mediolateral bodyweight distribution mechanism. The dashed circle shows that this mechanism takes place at the hip level. The vertical arrows show on which leg the bodyweight is most important; (B) Graphical representation of the mediolateral center of pressure location mechanism. The dashed circle shows that this mechanism takes place at the ankle level.

\section{Methods}

\subsection{Participants}

\subsubsection{Inclusion/exclusion criteria}

All the patients with PD were selected during consultations at Lille University Hospital's Neurology Department (Lille, France) with Professor Luc Defebvre. None of the patients met criteria for dementia (according to DSM IV) or cognitive decline. All the participants had to have a Mini-Mental Examination Score greater than 25 [19]. All the patients were instructed to take their last dose of antiparkinsonian medication on the evening before the study (i.e. more than 12 hours before the off-drug session). The study was performed on the following morning. All the participants had a good or adequately corrected visual acuity. If glasses or contact lenses were required in everyday life, they were worn during the tasks.

Participants were excluded if they (i) had a history or signs of vestibular, neurological or musculoskeletal disease (except for PD in the patient group), recurrent dizziness, dementia, or known hip- and ankle-related diseases or injuries, (ii) were taking any medication known to affect postural control, or (iii) had fallen in the previous six months (based on a question 
asked to the participants) or presented motor fluctuations or subclinical dyskinesia. This strict selection procedure was used to eliminate confounding variables and potential outliers.

The study protocol was approved by the local investigational review board (CPP NordOuest IV, Lille, France; reference: 11/25). All the participants gave their written, informed consent to participation.

\subsubsection{Characteristics of the study participants}

Fourteen patients with PD (9 males and 5 females) were included in the study. The mean \pm standard deviation (SD) age, bodyweight and height were respectively 64.93 years \pm 5.59 , $81.786 \mathrm{~kg} \pm 17.56$ and $1.71 \mathrm{~m} \pm 0.12$. Fourteen age-matched healthy controls ( 9 males and 5 females) were also included in the study. Their mean age, bodyweight and height were respectively 63.57 years $\pm 6.54,77.43 \mathrm{~kg} \pm 14.40$ and $1.70 \mathrm{~m} \pm 0.10$.

Parkinson's disease was diagnosed in accordance with the United Kingdom Parkinson's Disease Brain Bank criteria [20]. The mean time since disease onset was $7.43 \pm 4.69$ years. The mean Hoehn and Yahr stage in the patient group was 2.18 \pm 0.54 (range: 1-3). In the off-drug session, the patients' mean UPDRS motor score was 26.71 \pm 5.30 , the mean axial score (computed by summing UPDRS III items 18, 22, 27, 28, 29 and 30 [18]) was 8.93 \pm 4.07 , and the mean postural stability score (computed by summing UPDRS III items 18, 27, 28, 29, and 30 [21]) was $3.57 \pm 1.34$. On average, the patients were receiving a daily total levodopa equivalent dose (which takes account of both levodopa and dopamine agonists) of $743.21 \pm 227.18 \mathrm{mg}$. Once the first (off-drug) session had been completed, the patients received $150 \%$ of their usual morning equivalent levodopa dose, as is typical in studies of postural control (e.g. [8]).

\subsection{Apparatus}

An eye tracker (SensoMotoric Instruments, Teltow, Germany) was used to record eye movements (left-right and up-down) at a sampling frequency of $50 \mathrm{~Hz}$ (Figure 2). A magnetic tracking system (Liberty 240/8-8 System, Polhemus, Colchester, VT, USA) was used to record anteroposterior (AP) and ML head, neck and lower back linear displacements and angular yaw (left/right) and angular pitch (up/down) displacements at a sampling frequency of $240 \mathrm{~Hz}$. Markers were placed near the occiput (on a hat, for the head marker), near the seventh cervical vertebra (for the neck marker) and near the second lumbar vertebra (on a belt, for the lower back marker; Figure 2). We used three markers (instead of a single marker) to probe body sway and changes in body segment rotations at two body levels (head-on-trunk, and trunk-in-space; see below). A dual-top force platform (AccuSway, Biometrics, Orsay, France; Figure 2) was used to record COP displacements at a sampling frequency of $120 \mathrm{~Hz}$. The platform was placed $1.5 \mathrm{~m}$ away from the panoramic display (Figure 2). Two papers with printed lines were fixed onto the platform, in order to mark the standardized foot position (14 $\left.\mathrm{cm}, 17^{\circ} ;[22]\right)$.

A MATLAB script (written with MATLAB 7.10 software; The MathWorks, Natick, MA, USA) was used to project a black dot onto the panoramic display (see below) and to synchronize all the devices (the video projector, force platform, magnetic tracking system and eye tracker). 

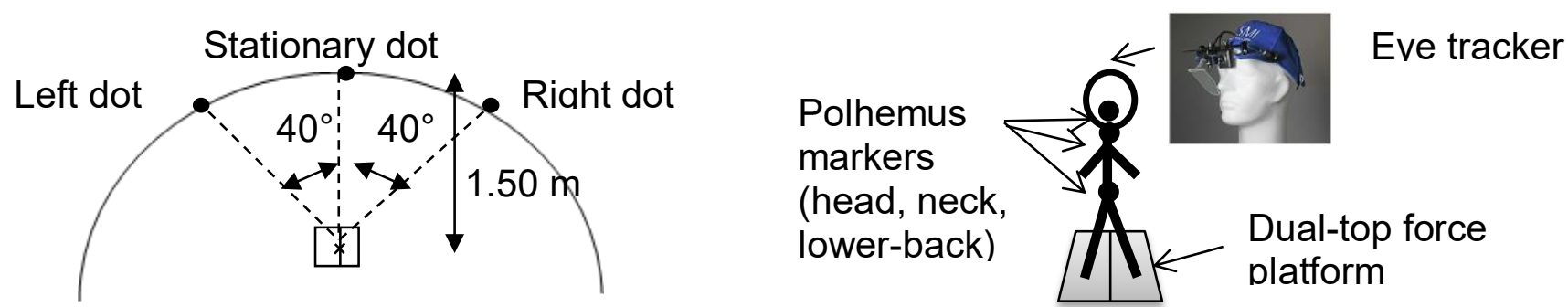

Figure 2. Description of the experimental setting. The left panel shows the position of the dual-top force platform placed $1.50 \mathrm{~m}$ away from a semicircular, panoramic display. The target (a black dot, subtending a visual angle of $5^{\circ}$ ) was presented either in a stationary position in front of the participant or alternately on the left and right (at $0.125 \mathrm{~Hz}$ or $0.25 \mathrm{~Hz}$ ) at a total visual angle of $80^{\circ}$. The right panel shows the eye tracker placed on the head of the participants, the head, neck, lower back markers of the Polhemus motion analysis system and the dual-top force platform.

\subsection{Visual tasks}

The study comprised two sessions of nine trials (three trials of three visual tasks). In the stationary gaze task, the participants had to fix a stationary black dot (subtending a visual angle of $5^{\circ}$ ) projected onto the panoramic display in front of them for thirty-five seconds. In the 0.125 and $0.25 \mathrm{~Hz}$ gaze-shift tasks, the participants had to fix a black dot $\left(5^{\circ}\right)$ that appeared $40^{\circ}$ to the left and $40^{\circ}$ the right from the $4^{\text {th }}$ to the $35^{\text {th }}$ second (Figure 2). For the first 3 second of both tasks, the black dot was presented in a stationary position in front of the participants. All trials were performed in a lightly room. The order in which the conditions were performed was randomized in the first session and then maintained in the second session.

In the stationary gaze task, the participants had to stand in a relaxed position but refrain from making any voluntary movements. In the 0.125 and $0.25 \mathrm{~Hz}$ gaze-shift tasks, the participants had to shift their gaze quickly from one target to the other in the way they found to be most comfortable. They could turn their eyes, head, shoulders and/or lower back as they liked. In contrast to our previous study [13] (and with a view to recording more natural, ecological behavior), we did not instruct the participants to avoid eye movement as much as possible. After having alerted the investigator, the participants could sit down and rest whenever they liked.

\subsection{Procedure}

On arrival at the laboratory, all participants were evaluated by a neurologist with expertise in the diagnosis of movement disorders (LD or $\mathrm{AD}$ ). Participants were given instructions for the sessions and were equipped with the eye tracker and the three magnetic tracking markers. Before starting each session, the patients and controls were seated on a stool placed just behind the force platform. Next, they stood bare-foot on the force platform with their feet placed at the standardized position (see 2.2. Apparatus) and performed the nine trials in the first session. We assessed motor status (UPDRS III score) under standardized conditions in the off-drug session (at $9 \mathrm{am}$ ) and then after acute levodopa administration (in the "best ondrug" session). The rest period between the two sessions was 45 min for the controls and between 45 and 60 min for the patients (depending on the neurologist's judgment of the 
medication's effectiveness). After the magnetic tracking markers and the eye tracker had been removed, the participants were free to move as they liked during the inter-session interval.

\subsection{Dependent variables and analyses}

\subsubsection{Linear displacements of body parts}

Displacements of the head, neck, lower back and COP were analyzed in terms of the corresponding range (R), SD and mean velocity (V).

\subsubsection{Postural control mechanisms}

In the first set of main analyses, we used a two-step procedure to calculate the contributions of the COP location $\left(\mathrm{COP}_{c}\right)$ and bodyweight distribution $\left(\mathrm{COP}_{v}\right)$ mechanisms to ML postural control during the visual tasks (see $[23,24]$ for details). In the first step, we used the equations published by Bonnet et al. [23]:

$$
\begin{aligned}
& C O P(t)=\operatorname{COP}_{l}(t) \frac{R_{v l}(t)}{R_{v l}(t)+R_{v r}(t)}+\operatorname{COP}_{r}(t) \frac{R_{v r}(t)}{R_{v l}(t)+R_{v r}(t)} \\
& \operatorname{COP}_{c}(t)=C O P_{l}(t) \times \operatorname{meanR}_{v l}+C O P_{r}(t) \times \operatorname{meanR}_{v r} \\
& \operatorname{COP}_{v}(t)=\text { meanCOP }_{l} \frac{R_{v l}(t)}{R_{v l}(t)+R_{v r}(t)}+\text { meanCOP }_{r} \frac{R_{v r}(t)}{R_{v l}(t)+R_{v r}(t)}
\end{aligned}
$$

In equation 1, the COP displacement (the response variable) was calculated as the sum of $\mathrm{COP}_{l}(\mathrm{t})$ and $\mathrm{COP}_{r}(\mathrm{t})$ by taking into account $\mathrm{R}_{v l}(\mathrm{t})$ and $\mathrm{R}_{v r}(\mathrm{t})$. This equation is conventionally designed to calculate the COP displacement when participants stand on two platforms (as in [13-15,23,25]. In equation 2, the proportion of COP displacement explained by the COP location mechanism $\left(\mathrm{COP}_{c}\right)$ was calculated by controlling for the $\mathrm{COP}$ displacement explained by the COP bodyweight distribution mechanism $\left(\mathrm{COP}_{v}\right)$ (assuming constant mean values of $\mathrm{R}_{v l}$ and $\mathrm{R}_{v r}$ ). In equation 3, the COP displacement explained by the $\mathrm{COP}_{v}$ was next calculated by controlling for the COP displacement explained by the $\mathrm{COP}_{c}$ (assuming constant mean values of $\mathrm{COP}_{l}$ and $\mathrm{COP}_{r}$ ). It should be noted that we used the term "COP" hereafter to refer to "COP net" (the term conventionally used in the literature on postural control $[14,15,23,26]) . \mathrm{COP}_{v}$ and $\mathrm{COP}_{c}$ are unitless.

Once the three time series had been obtained, we assessed each mechanism's contribution. For this second step in the analysis, the amplitudes and active contributions of $\mathrm{COP}_{c}$ and $\mathrm{COP}_{v}$ were considered to be dependent variables. The amplitude contribution concerned the amplitude or strength of the mechanisms (i.e. weaker or stronger), while the active contribution concerned the time at which the mechanisms were activated (i.e. whether or not the mechanism was active at the moment at which the COP moved; see [23]). The amplitude contribution was calculated in both absolute and relative terms. The absolute amplitude contribution concerned the variability of $\mathrm{COP}_{c}(\mathrm{t})$ and $\mathrm{COP}_{v}(\mathrm{t})$ without any reference to the variability of $\operatorname{COP}(\mathrm{t})$. This analysis determined whether each mechanism's contribution was stronger or weaker in the visual tasks, irrespective of any increase or decrease in COP displacement. The relative amplitude contribution concerned the variability of $\mathrm{COP}_{c}(\mathrm{t})$ or $\mathrm{COP}_{v}(\mathrm{t})$ with reference to the variability of $\mathrm{COP}(\mathrm{t})\left(\% \mathrm{SD} \mathrm{COP}_{c} / \mathrm{COP}\right.$ and $\% \mathrm{SD} \mathrm{COP}_{v} / \mathrm{COP}$, respectively). This analysis served to establish whether the strength of each mechanism was appropriate for controlling the COP displacement in each visual task. The active contributions of $\mathrm{COP}_{c}$ and $\mathrm{COP}_{v}$ were calculated along with the cross-correlation coefficients for $\mathrm{COP}_{c}$ vs. $\mathrm{COP}$ and for $\mathrm{COP}_{v}$ vs. COP, as in previous studies [13-15,23,26]. 


\subsubsection{Angular displacements of body parts}

The second set of main analyses concerned body segment rotations. In fact, we wanted to assess both disease-related and levodopa-related changes in head, neck and/or lower back angular rotations (which would be consistent with H3) to explain the reportedly higher amplitude of postural sway in patients during performance of the visual tasks (which would be consistent with H1). Head-on-trunk and trunk-in-space angular displacements were used to quantify body rotations. The head-on-trunk angular displacements concerned rotations of the head relative to the trunk, and the trunk-in-space angular displacements concerned rotations of the trunk relative to the stationary ground. We analyzed angular yaw and pitch (up/down) displacements of these segments.

Angular variables were used to quantify body segment rotations used in performing the task but not to quantify body sway per se. These variables showed how the participants moved their body segments when performing the $0.125 \mathrm{~Hz}$ and $0.25 \mathrm{~Hz}$ tasks. In contrast, linear variables related to the COP and body markers were only used to quantify COP displacements and body sway. It is important to note that linear body displacements can be affected by angular body rotations. For example, when the head turns $40^{\circ}$ to the right, the head marker necessarily moves to the left - hence increasing ML linear displacements (in terms of R, SD and V). Although we were aware of this issue, we could not control for it; in other words, we could not differentiate between ML linear displacements caused by linear body sway and ML linear displacements caused by angular body rotation.

\subsubsection{Angular displacements of the eye (eye movements)}

The time series for eye-in-orbit angular displacements were calculated to (i) check the participants' compliance with the task's instructions and (ii) analyze levodopa-related and disease-related impairments in eye movements (consistent with H4). The time series were obtained as described in Bonnet et al. [13]. These angular displacements concerned rotations of the eyes relative to the orbit. We analyzed the mean and SD of the time series and (in the 0.125 and $0.25 \mathrm{~Hz}$ tasks only) the transition time from one target to the other. The mean and SD of the eye-in-orbit angular position were calculated separately for reaching the left and right targets. The mean eye-in-orbit angular position was used to analyze the extent to which the eyes moved from one target to another, by means of subtracting the mean positions on the right and left targets (see [13]). The SD reflected the eye's stability once the target had been reached; the greater the SD, the greater the variability in the eye's position.

\subsubsection{Analyses}

In all tasks, the participants looked at the stationary dot in front of them for the first 3 seconds in each trial (see 2.3. Visual tasks). Hence, only the last 32 seconds of data of each trial were analyzed. Furthermore, the data for all three trials per condition were averaged. All statistical analyses were performed with Statistica software (version 10, Statsoft Inc., Tulsa, OK, USA). Prior to the main, we searched for the presence of outliers in the time series with Boxplots. If outliers were not present, the variables were analyzed in three-way repeatedmeasures analyses of variance (ANOVAs) with group, visual task and session as factors. When outliers were found, the dependent variables were analyzed with (i) non-parametric Wilcoxon tests for intertask comparisons in the two sessions in each group separately, and (ii) non-parametric Mann-Whitney $U$ tests for inter-group comparisons in each visual condition in both sessions separately. The analyses were not simplified by subtracting the data (on-drug minus off-drug), for two reasons: (i) interaction effects in the three-way ANOVAs were sufficiently powerful tests of our hypotheses, and (ii) the three-way ANOVAs were useful for 
testing the degree of similarity between our previous data and the present data (the study's secondary objective). The threshold for statistical significance was set to $P<0.05$ for all analyses.

Possible intergroup differences in physical characteristics (age, bodyweight, and height) were tested in ANOVAs. To test the initial hypothesis (H1) and the primary hypotheses $(\mathrm{H} 2$, $\mathrm{H} 3$, and H4), we looked for significant interaction effects (group $\times$ section, and group $\times$ task $\times$ section) in the repeated-measures ANOVAs. When the data had to be tested with nonparametric tests, we simply tested differences between groups and sections. To test H5, we were simply interested in significant differences in the clinical variables between the off-drug and on-drug sessions. To analyze the secondary objective (differences between studies in the off-drug session), we did not perform new analyses but only considered significant interaction effects (group $\times$ task, and group $\times$ task $\times$ section) in the available repeated-measures ANOVAs and intergroup differences in the non-parametric tests. In the results section below, we combined our analyses rather than separating them so as to clearly summarize the results and describe trends in behavioral data.

\section{Results}

\subsection{Physical characteristics of the two study groups}

There were no intergroup differences in age $(F(1,26)=0.35, P>0.05)$, bodyweight $(F(1,26)=0.53, P>0.05)$ and height $(F(1,26)=0.05, P>0.05)$.

\subsection{Rest periods during the two sessions}

As explained in the Methods section, the participants were invited to rest between the two sessions and they did so. During each session, they were also invited to tell us if they wanted/needed to stop a few minutes. However, none of the patients and controls asked to stop the study at any time.

\subsection{Significant effects of group on the behavioral dependent variables}

\subsubsection{COP and body sway in the visual tasks in the two sessions (to test H1)}

Parametric analyses. The three-way repeated-measures ANOVAs concerned COP, head, neck and lower back variables in the ML axis and COP variables in the AP axis, since there was no outlier for these time-series. Firstly, a significant effect of a group $\times$ session interaction was found for COP $\mathrm{R}_{\mathrm{ML}}$, COP $\mathrm{R}_{\mathrm{AP}}$, COP $\mathrm{SD}_{\mathrm{ML}}$, COP $\mathrm{SD}_{\mathrm{AP}}$, neck $\mathrm{R}_{\mathrm{ML}}$, neck $\mathrm{SD}_{\mathrm{ML}}$ and lower back $\mathrm{V}_{\mathrm{ML}}\left(F_{s}(1,26)>5.04, P<0.05\right.$; Figure 3$)$. Secondly, a significant effect of a visual task $\times$ group interaction was found for $\operatorname{COP} \mathrm{V}_{\mathrm{ML}}(F(2,52)=3.54, P<0.05$; Figure $3 \mathrm{E})$, and significant effects of a group $\times$ session $\times$ visual task interaction were found for COP $\mathrm{R}_{\mathrm{AP}}$, lower back $\mathrm{V}_{\mathrm{ML}}$ and neck $\mathrm{R}_{\mathrm{ML}}\left(F_{s}(2,52)>4.16, P<0.05\right.$, Figure $\left.3 \mathrm{~B}, 3 \mathrm{~F}, 3 \mathrm{G}\right)$. This was true in the on-drug session for several variables (Figure 3B, 3F, 3G) and, most particularly, for COP $\mathrm{V}_{\mathrm{ML}}$ in both sessions (Figure $3 \mathrm{E}$ ). Thirdly, significant visual task $\mathrm{x}$ group interaction effects were found for head $\mathrm{R}_{\mathrm{ML}}, \mathrm{SD}_{\mathrm{ML}}$ and $\mathrm{V}_{\mathrm{ML}}\left(F_{s}(2,52)>7.61, P<0.05\right)$. The patients with PD exhibited significantly lower and slower head linear ML displacements than the controls in both the 0.125 and $0.25 \mathrm{~Hz}$ tasks but not in the stationary gaze task. Fourthly, we observed significant main effects of group that were consistent with the findings described above. Indeed, the patients with PD displayed significantly greater and quicker COP displacements than the controls for COP $\mathrm{R}_{\mathrm{AP}}$ (Figure $3 \mathrm{~B}$ ) and COP $\mathrm{V}_{\mathrm{AP}}$ but significantly smaller head displacements than the controls for head $\mathrm{R}_{\mathrm{ML}}$ and $\mathrm{SD}_{\mathrm{ML}}\left(F_{s}(1,26)>5.05, P<0.05\right)$. 
A
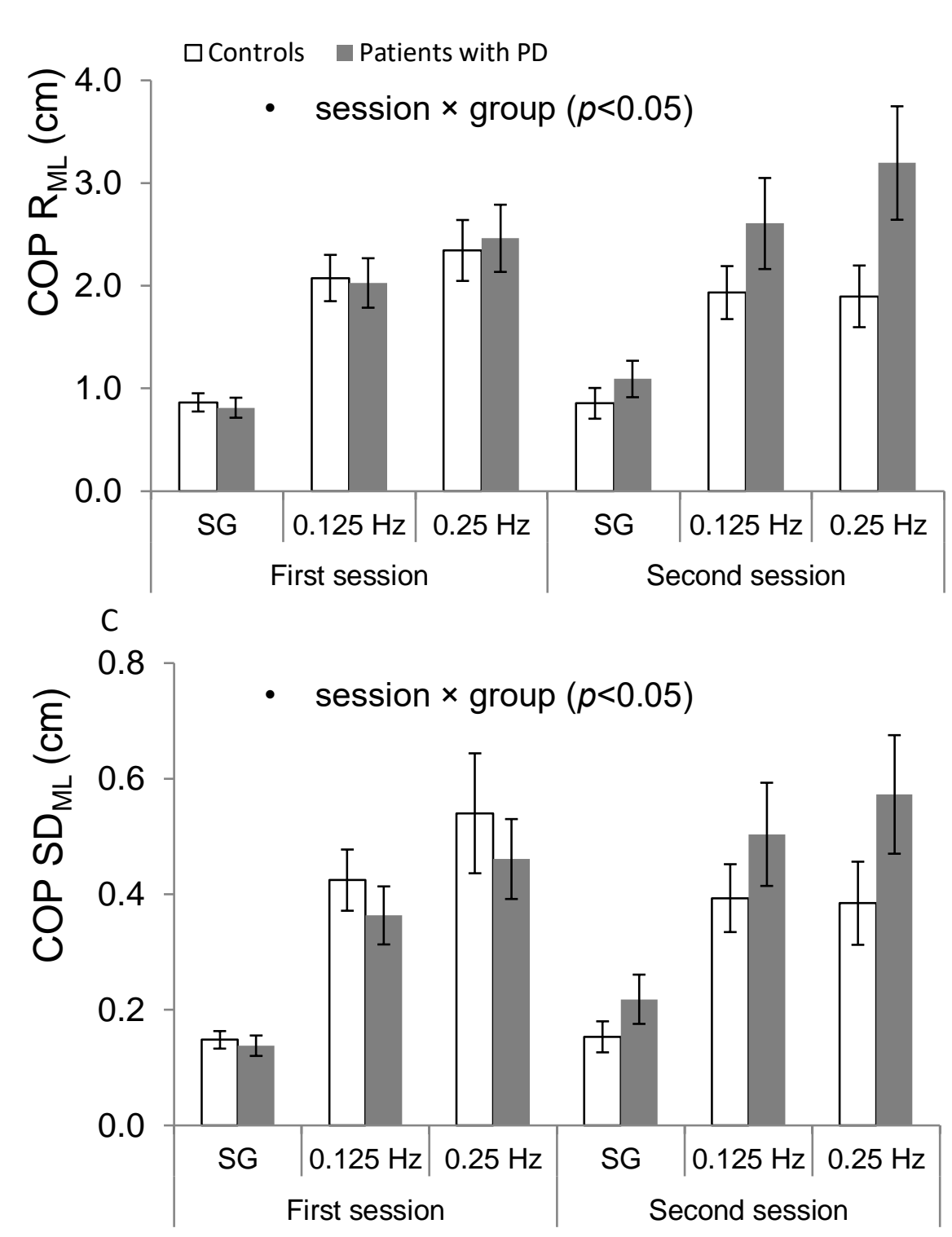
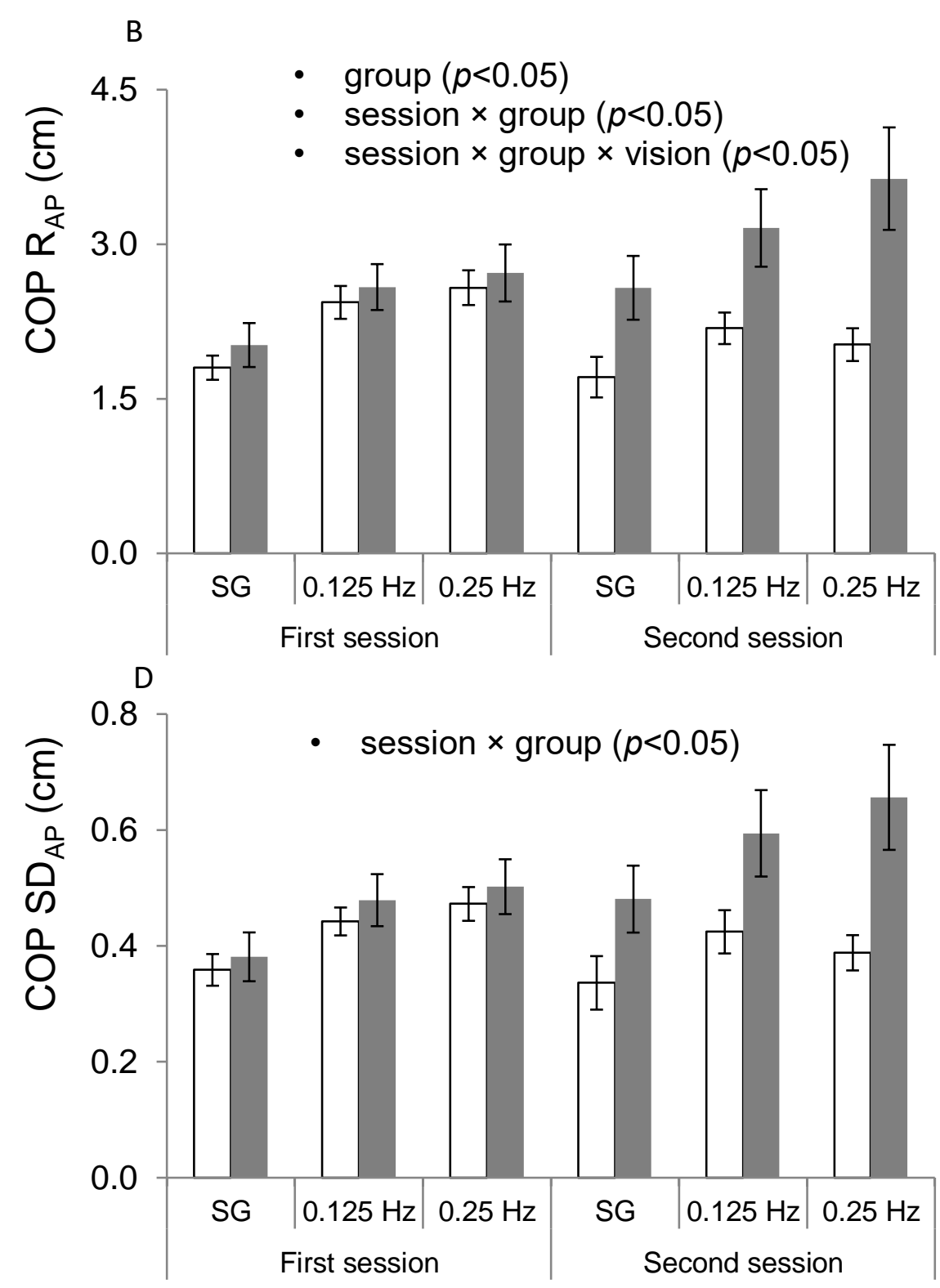

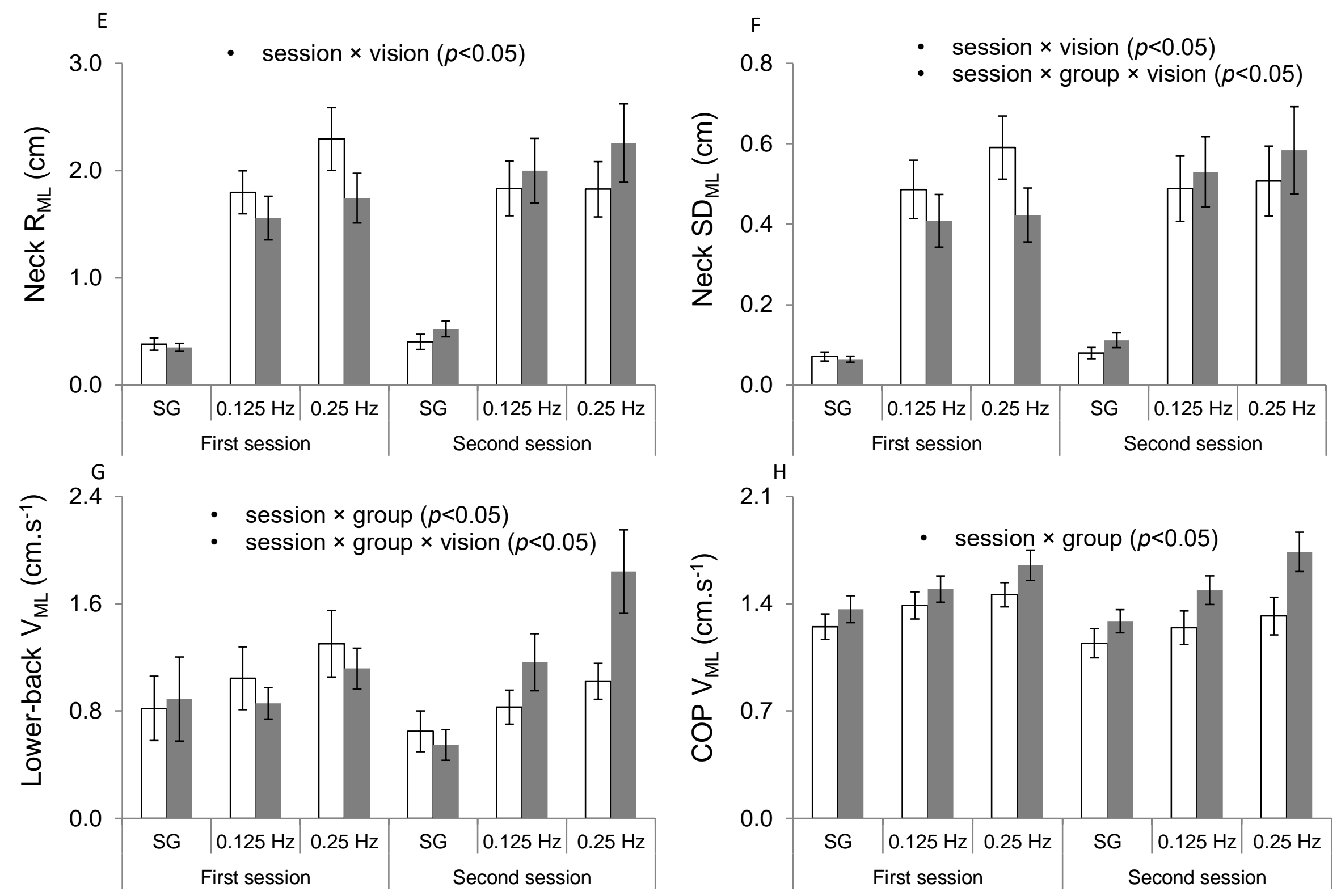
Figure 3. Significant main and/or interaction effects related to the group (patients with Parkinson's disease (PD) vs. healthy controls) in the three-ways repeated measures ANOVA for center of pressure (COP), head, neck and lower back displacements. These significant effects were found specifically for COP range in the mediolateral and anteroposterior axes ( $\mathrm{R}_{\mathrm{ML}}, \mathrm{R}_{\mathrm{AP}}$; Figure $3 \mathrm{~A}$ and $3 \mathrm{~B}$ ), COP standard deviation in the ML and $\mathrm{AP}$ axes ( $\mathrm{SD}_{\mathrm{ML}}, \mathrm{SD}_{\mathrm{AP}}$; Figure $3 \mathrm{C}$ and $3 \mathrm{D}$ ), COP mean velocity in the $\mathrm{ML}$ axis $\left(\mathrm{V}_{\mathrm{ML}}\right.$; Figure $3 \mathrm{E}$ ), lower back $\mathrm{V}_{\mathrm{ML}}(\mathrm{Figure} 3 \mathrm{~F})$ neck $\mathrm{R}_{\mathrm{ML}}$ (Figure $3 \mathrm{G}$ ) and neck $\mathrm{SD}_{\mathrm{ML}}$ (Figure $3 \mathrm{H}$ ). In the stationary gaze task (SG), the participants stared at a black dot in front of them (subtending a visual angle of $5^{\circ}$ ). In the $0.125 \mathrm{~Hz}$ and $0.25 \mathrm{~Hz}$, they gazed a black dot moving $40^{\circ}$ to the left and $40^{\circ}$ to the right at $0.125 \mathrm{~Hz}$ and $0.25 \mathrm{~Hz}$. In the first and second sessions, the patients were off- and on-drug, respectively. The error bars represent the standard error of the mean. $P<0.05$. The significant session $\times$ vision, session $\times$ group and session $\times$ group $\times$ vision effects are written at the top of each figure but not represented by $*$ (we recall that no post-hoc test was performed).
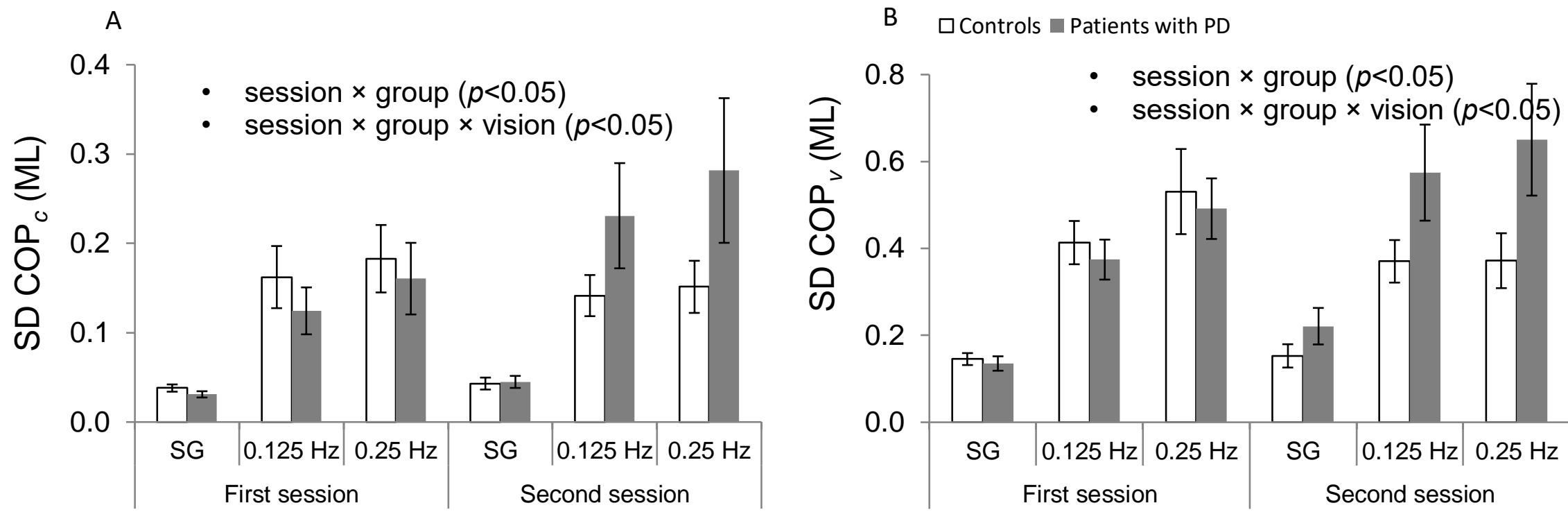

Figure 4. Significant session $\times$ group and session $\times$ group $\times$ vision interaction effects in the three-ways repeated measures ANOVA for the standard deviation (SD) of the center of pressure vertical and change $\left(\mathrm{COP}_{v}\right.$ and $\left.\mathrm{COP}_{c}\right)$ displacements. In the stationary gaze task $(\mathrm{SG})$, the participants stared at a black dot in front of them (subtending a visual angle of $5^{\circ}$ ). In the $0.125 \mathrm{~Hz}$ and $0.25 \mathrm{~Hz}$, they gazed a black dot moving $40^{\circ}$ to the left and $40^{\circ}$ to the right at $0.125 \mathrm{~Hz}$ and $0.25 \mathrm{~Hz}$. In the first and second sessions, the patients were off- and on-drug, respectively. The error bars represent the standard error of the mean. $P<0.05$. There is no unit for $\mathrm{SD} \mathrm{COP}_{v}$ and $\mathrm{SD} \mathrm{COP}_{c}$. There is no $(*)$ as the figure itself shows significant interaction effects (no post-hoc performed). However, 'session $\times$ group' and 'session $\times$ group $\times$ vision' are written at the top of the figure to show the significant interaction effects. 
Table 1. Results of the non-parametric analyses comparing linear and angular body displacements between the first and second sessions for both patients with Parkinson's Disease (PD) and controls separately. The variables were the range (R), the standard deviation (SD) and the velocity (V) of the head, neck and lower back displacement in the anteroposterior (AP) axis and pitch direction. In the first and second sessions, the participants performed three visual tasks, i.e. the stationary-gaze task, the $0.125 \mathrm{~Hz}$ task and the $0.25 \mathrm{~Hz}$ task (see text for the definition of these tasks). $(+),(*)$ and $(\times)$ show a significant difference between the first and second session in the stationary-gaze, $0.125 \mathrm{~Hz}$ and $0.25 \mathrm{~Hz}$ visual tasks, respectively.

\begin{tabular}{|c|c|c|c|c|c|c|c|}
\hline Groups & Dependent variables & $\begin{array}{l}\text { Stationary-gaze } \\
\text { task, first session }\end{array}$ & $\begin{array}{l}\text { Stationary-gaze } \\
\text { task, } \quad \text { second } \\
\text { session }\end{array}$ & $\begin{array}{l}0.125 \mathrm{~Hz} \text { task, } \\
\text { first session }\end{array}$ & $\begin{array}{l}0.125 \mathrm{~Hz} \text { task, } \\
\text { second session }\end{array}$ & $\begin{array}{l}0.25 \mathrm{~Hz} \text { task, first } \\
\text { session }\end{array}$ & $\begin{array}{l}0.25 \mathrm{~Hz} \text { task, } \\
\text { second session }\end{array}$ \\
\hline \multirow{7}{*}{$\begin{array}{l}\text { Patients } \\
\text { with PD }\end{array}$} & Head $R_{A P}(\mathrm{~cm})$ & $1.10 \pm 0.43$ & $1.41 \pm 0.51(+)$ & $2.03 \pm 0.34$ & $2.48 \pm 0.51(*)$ & $2.03 \pm 0.33$ & $2.54 \pm 0.61(\times)$ \\
\hline & Neck R $R_{A P}(\mathrm{~cm})$ & $1.04 \pm 0.40$ & $1.26 \pm 0.47(+)$ & $1.50 \pm 0.44$ & $1.89 \pm 0.65(*)$ & $1.46 \pm 0.45$ & $2.06 \pm 0.81(\times)$ \\
\hline & Head $\mathrm{SD}_{\mathrm{AP}}(\mathrm{cm})$ & $0.24 \pm 0.10$ & $0.30 \pm 0.11(+)$ & $0.48 \pm 0.09$ & $0.59 \pm 0.16$ & $0.45 \pm 0.07$ & $0.60 \pm 0.16(\times)$ \\
\hline & Neck $\mathrm{SD}_{\mathrm{AP}}(\mathrm{cm})$ & $0.22 \pm 0.09$ & $0.27 \pm 0.10(+)$ & $0.35 \pm 0.11$ & $0.45 \pm 0.17$ & $0.31 \pm 0.09$ & $0.48 \pm 0.20(\times)$ \\
\hline & Head $V_{A P}\left(\mathrm{~cm} \cdot \mathrm{s}^{-1}\right)$ & $0.77 \pm 0.24$ & $0.92 \pm 0.37(+)$ & $1.06 \pm 0.28$ & $1.23 \pm 0.39$ & $1.36 \pm 0.32$ & $1.58 \pm 0.43(\times)$ \\
\hline & Lower back $\mathrm{V}_{\mathrm{AP}}\left(\mathrm{cm} \cdot \mathrm{s}^{-1}\right)$ & $0.36 \pm 0.21$ & $0.49 \pm 0.35(+)$ & $0.48 \pm 0.19$ & $0.60 \pm 0.32(*)$ & $0.56 \pm 0.22$ & $0.81 \pm 0.43$ \\
\hline & Neck $S_{\text {pitch }}(\mathrm{cm})$ & $0.34 \pm 0.15$ & $0.43 \pm 0.17(+)$ & $0.92 \pm 0.59$ & $1.17 \pm 0.48$ & $1.36 \pm 1.51$ & $1.13 \pm 0.43$ \\
\hline \multirow{4}{*}{ Controls } & Head $V_{A P}\left(\mathrm{~cm} \mathrm{~s}^{-1}\right)$ & $0.79 \pm 0.32$ & $0.73 \pm 0.30(+)$ & $1.16 \pm 0.33$ & $1.10 \pm 0.30$ & $1.56 \pm 0.37$ & $1.47 \pm 0.35$ \\
\hline & $\operatorname{Neck} V_{A P}\left(\mathrm{~cm} \cdot \mathrm{s}^{-1}\right)$ & $0.65 \pm 0.40$ & $0.57 \pm 0.19$ & $1.32 \pm 1.04$ & $0.91 \pm 0.42(*)$ & $1.37 \pm 1.07$ & $0.99 \pm 0.40$ \\
\hline & Neck $R_{\text {pitch }}(\mathrm{cm})$ & $1.75 \pm 0.64$ & $1.75 \pm 0.66$ & $3.90 \pm 1.25$ & $4.00 \pm 1.86$ & $4.38 \pm 1.57$ & $4.00 \pm 1.86(\times)$ \\
\hline & Neck $V_{\text {pitch }}(\mathrm{cm})$ & $3.54 \pm 2.52$ & $3.07 \pm 1.42$ & $8.08 \pm 7.36$ & $5.88 \pm 4.75(*)$ & $8.69 \pm 7.27$ & $6.76 \pm 4.67$ \\
\hline
\end{tabular}


Non-parametric analyses. The non-parametric analyses concerned head, neck and lower back variables in the AP axis and pitch direction, since there was some outliers in these timeseries. The patients with PD exhibited a significantly higher rank for linear AP and angular pitch displacements in the on-drug session than in the off-drug session. This was true for head $\mathrm{R}_{\mathrm{AP}}$ and neck $\mathrm{R}_{\mathrm{AP}}$ in the three visual tasks, for head $\mathrm{SD}_{\mathrm{AP}}$, neck $\mathrm{SD}_{\mathrm{AP}}$ and head $\mathrm{V}_{\mathrm{AP}}$ in the $0.25 \mathrm{~Hz}$ and stationary gaze tasks, for lower back $\mathrm{V}_{\mathrm{AP}}$ in the $0.125 \mathrm{~Hz}$ and stationary gaze tasks, and for neck $\mathrm{SD}_{\text {pitch }}$ in the stationary gaze task (Table 1). In contrast, the controls exhibited a significantly lower rank for linear AP and angular pitch displacements in the second session than in the first one. This was true for head $V_{A P}$ in the stationary gaze task, for neck $V_{A P}$ in the $0.125 \mathrm{~Hz}$ task, for neck $R_{\text {pitch }}$ in the $0.25 \mathrm{~Hz}$ task and for neck $\mathrm{V}_{\text {pitch }}$ in the $0.125 \mathrm{~Hz}$ task (Table 1). Overall, the patients with PD exhibited greater linear and angular body motions in the on-drug session than in the off-drug session, whereas the controls exhibited lower linear and angular body motions in the second session than in the first session.

\subsubsection{Postural control mechanisms in the visual tasks in the two sessions (to test H2)}

The time-series of COP location and bodyweight distribution mechanisms did not show any outliers. Hence, these variables were analyzed in three-way repeated measure ANOVAs. Analyses of the active contributions ( $\mathrm{COP}_{v}$ vs. $\mathrm{COP}$ and $\mathrm{COP}_{v}$ vs. $\left.\mathrm{COP}\right)$ and relative amplitude contributions of the postural control mechanisms (\% SD COP $/ \mathrm{COP}$ and $\% \mathrm{SD}$ $\mathrm{COP}_{v} / \mathrm{COP}$ ) did not show any significant group effects $(n s)$. Analyses of the absolute amplitude of the mechanisms' contributions $\left(\mathrm{SD} \mathrm{COP}_{v}\right.$ and $\left.\mathrm{SD} \mathrm{COP}_{c}\right)$ revealed significant effects of a group $\times$ session interaction $\left(F_{s}(1,26)>4.79, P>0.05\right.$, Figure $4 \mathrm{~A}$ and $4 \mathrm{~B}$, respectively) and a group $\times$ session $\times$ visual task interaction $\left(F_{s}(2,52)>4.18, P>0.05\right.$, Figure $4 \mathrm{~A}$ and $4 \mathrm{~B})$. The absolute amplitude of the contributions of the ML postural control mechanisms in the 0.125 and $0.25 \mathrm{~Hz}$ tasks were greater for the patients with PD in the ondrug session than for the controls (Figure 4A and 4B).

\subsubsection{Body segment rotations during the visual tasks in the two sessions (to test H3)}

In the off-drug session and considering the two gaze-shift tasks together, the eyes-in-orbit, head-on-trunk and trunk-in-space movements respectively accounted for 27\%, 60\% and 13\% of the patients' total movement (where $100 \%$ is equivalent to $80^{\circ}$ ). In the controls, these body part movements respectively accounted for $14 \%, 71 \%$ and $15 \%$ of the total movement. In the second session (i.e. the on-drug session for the patients), eyes-in-orbit, head-on-trunk and trunk-in-space movements respectively accounted for $22 \%, 64 \%$ and $14 \%$ of the total movement in the patients and $14 \%, 72 \%$ and $14 \%$ of the total movement in the controls.

The time-series of the head-on-trunk and trunk-in-space angular displacements did not show any outliers. The three-way repeated-measures ANOVAs for the head-on-trunk and trunk-in-space angular displacements did not reveal any significant effects $\left(F_{s}<3.05, P>0.05\right)$. Overall, our results showed that the patients and controls rotated their head and trunk in a similar manner when performing the gaze-shift tasks.

\subsubsection{Eye movements and visual task performance during the visual tasks in the two sessions (to test $\mathrm{H} 4$ )}

All the participants performed all the gaze shifts as instructed in terms of frequency, timing and amplitude. 
The time-series of the mean and standard deviation of the eye-in-orbit angular position did not show any outliers. Hence, these variables were analyzed in three-way repeated measure ANOVAs. The repeated-measures ANOVA for the mean eye-in-orbit angular position in the 0.125 and $0.25 \mathrm{~Hz}$ visual tasks showed a main effect of group $(F(1,26)=9.23, P<0.05)$ and a main effect of visual task $(F(1,26)=4.34, P<0.05)$. Overall, the patients with PD rotated their eyes significantly more than the controls in both sessions (Table 2). Both groups moved their eyes less in the $0.25 \mathrm{~Hz}$ task than in the $0.125 \mathrm{~Hz}$ task (Table 2).

Table 2. Coordination of the different segments (eyes and body) to perform the $0.125 \mathrm{~Hz}$ and $0.25 \mathrm{~Hz}$ tasks. The Eyes-in-orbit concerned rotations of the eyes relative to the orbit. The headon-trunk concerned rotations of the head relative to the trunk and the trunk-in-space concerned rotations of the trunk relative to the stationary ground. The rotations are described in degrees $\left({ }^{\circ}\right)$.

\begin{tabular}{|c|c|c|c|c|}
\hline Visual tasks & Groups & Eyes-in-orbit $\left(^{\circ}\right)$ & $\begin{array}{l}\text { Head-on-trunk } \\
\left(^{\circ}\right)\end{array}$ & $\begin{array}{l}\text { Trunk-in-space } \\
\left(^{\circ}\right)\end{array}$ \\
\hline \multirow[t]{2}{*}{$\begin{array}{l}0.125 \mathrm{~Hz} \text { OF- } \\
\text { drug }\end{array}$} & $\begin{array}{l}\text { Patients with } \\
\text { PD }\end{array}$ & $20.73 \pm 8.42(*)$ & $55.39 \pm 10.20$ & $10.93 \pm 10.05$ \\
\hline & Controls & $12.52 \pm 7.61$ & $56.23 \pm 12.24$ & $10.78 \pm 7.85$ \\
\hline \multirow[t]{2}{*}{$\begin{array}{lll}0.25 & \mathrm{~Hz} & \mathrm{OF}- \\
\text { drug } & & \\
\end{array}$} & $\begin{array}{l}\text { Patients with } \\
\text { PD }\end{array}$ & $21.72 \pm 10.89(*)$ & $44.08 \pm 23.31$ & $10.66 \pm 10.86$ \\
\hline & Controls & $10.53 \pm 5.12$ & $59.30 \pm 19.21$ & $13.90 \pm 14.00$ \\
\hline \multirow[t]{2}{*}{$\begin{array}{l}0.125 \mathrm{~Hz} \text { ON- } \\
\text { drug }\end{array}$} & $\begin{array}{l}\text { Patients with } \\
\text { PD }\end{array}$ & $19.59 \pm 10.35(*)$ & $52.85 \pm 9.93$ & $12.62 \pm 10.04$ \\
\hline & Controls & $12.47 \pm 7.25$ & $57.02 \pm 13.24$ & $10.77 \pm 7.30$ \\
\hline \multirow[t]{2}{*}{$\begin{array}{lll}0.25 & \mathrm{~Hz} & \mathrm{ON}- \\
\text { drug } & & \\
\end{array}$} & $\begin{array}{l}\text { Patients with } \\
\text { PD }\end{array}$ & $18.12 \pm 10.33(*)$ & $50.36 \pm 14.73$ & $10.62 \pm 10.32$ \\
\hline & Controls & $9.63 \pm 4.67$ & $59.56 \pm 12.24$ & $11.31 \pm 8.95$ \\
\hline
\end{tabular}

(*) shows a significant difference between patients with Parkinson's Disease (PD) and controls

The repeated-measures ANOVA for the variability of the eye-in-orbit angular position showed a significant main effect of group $(F(1,26)=9.93, P<0.05)$ and visual task $(F(1,26)=93.59, P<0.05)$, and a significant effect of a group $\times$ visual task interaction $(F(1,26)=7.94, P<0.05)$. The patients with PD exhibited greater variability in their eye-inorbit angular position than the controls in both the 0.125 and $0.25 \mathrm{~Hz}$ visual tasks (patients: $9.06^{\circ} \pm 4.54^{\circ}$; controls: $4.79^{\circ} \pm 1.98^{\circ}$ ) but not in the stationary gaze task (patients: $0.65^{\circ} \pm 0.32^{\circ}$; controls: $\left.0.57^{\circ} \pm 0.17^{\circ}\right)$.

The repeated-measures ANOVA for the transition time from one target to the other only showed a main effect of the visual task $(F(1,26)=56.89, P<0.05)$. The participants moved their eyes more rapidly from one target to the other in the $0.25 \mathrm{~Hz}$ task $(0.83 \pm 0.20$ seconds $)$ than in the $0.125 \mathrm{~Hz}$ tasks $(1.00 \pm 0.23$ seconds).

\subsection{The clinical impact of acute levodopa administration on patients with PD (to test H5)}

All three clinical scores were significantly lower $(P<0.05)$ in the on-drug session than in the off-drug session, i.e. the mean \pm SD motor UPDRS (11.50 \pm 4.99 vs. 26.71 \pm 5.30 , 
respectively; $F(1,13)=116.26)$, axial rigidity ( $3.79 \pm 3.02$ vs. $8.93 \pm 4.07$, respectively; $F(1,13)=44.69)$ and postural instability $(1.57 \pm 1.28$ vs. $3.57 \pm 1.34$ respectively $F(1,13)=24.27)$.

\section{Discussion}

The present study was designed to (i) assess the impact of acute levodopa administration on postural control (body sway, body rotation, and the mechanisms involved), task performance and eye movements in various visual tasks, and (ii) to confirm a previous report on off-drug performance [13] in patients with PD. The effects of levodopa administration on postural control were negative or neutral but never positive. Indeed, the patients exhibited significantly greater COP and body sway in the on-drug session than in the off-drug session. Body segment rotations and eye movements were similar in the on-drug and off-drug sessions. Moreover, in the on-drug session, the patients with PD were not able to adjust the contribution of their mechanisms enough to avoid swaying more than the healthy controls. Remarkably, the patients were able to adjust the contribution of their mechanisms significantly more than the healthy controls could - but these adjustments were still insufficient to prevent an increase in postural sway (especially in the lower back region).

As expected (H5), levodopa significantly improved the patients' functional status. Indeed, the patients exhibited significantly lower UPDRS III, rigidity and postural instability scores in the on-drug session than in the off-drug session. Although levodopa administration did not improve the visual task performance per se, an improvement was not really necessary. Indeed, in the on-drug condition, the patients with PD performed the active 0.125 and $0.25 \mathrm{~Hz}$ tasks as well as the controls did. However, the medication did not reduce the variability of the patients' mean eye-in-orbit position observed in the $0.125 \mathrm{~Hz}$ and $0.25 \mathrm{~Hz}$ tasks, which was significantly greater than in the controls in both off-drug and on-drug sessions. Unexpectedly (see H4), medication therefore had no effect.

We expected that levodopa administration would lead the patients with PD to sway significantly more than the controls - especially in the gaze-shift tasks (H1). Our hypothesis was validated by the AP and ML data for several body regions (Figure 3A, B, C, D, E, F and $\mathrm{G}$; Table 1). In the second (on-drug) session, the patients' increase in postural sway was sometimes large enough to produce significant main effects of group in an analysis of the two sessions combined (see Figures 3B and Table 1). Taken as a whole, these results are in agreement with the literature findings $[3,6,9,10,27]$ and extend them to many body segments (COP, lower back, neck, and head).

In contrast to the results for the patients, the control participants swayed less in the AP axis during the second session than during the first one (Table 1). This effect may be due to practice or habituation but was not due to learning, since the movements required for the task were very simple and well-practiced in everyday activities (humans indeed rotate their head all the time during the day). This positive influence of practice on postural sway has already been reported by Tarantola et al. [28] in healthy adults (18-49 years) performing "eyes open" and "eyes closed" quiet stance tasks. We assume that the difference between the controls and the patients was due to levodopa rather than to fatigue, since the sessions in our present study were quite short (nine trials, each lasting 35 seconds, and performed quickly one after another). The participants rested for $45 \mathrm{~min}$ to 1 hour before performing the same nine, short trials again. Moreover, the patients did not have late-stage PD (Hoehn and Yahr score: $2.18 \pm 0.54)$.

A key finding of the present study is that the patients moved their lower back more rapidly in the ML and AP axes in the on-drug session than in the off-drug session - especially during the $0.25 \mathrm{~Hz}$ task (Figure 3F; Table 1). This was expected (H1), on the basis on our previous results [13]. As there was no particular reason for the patients to move the lower 
back region more quickly (especially given the lack of greater yaw rotation (Table 2)), this significant effect may reveal the presence of an unsafe postural strategy. Indeed, displacement of the heavy lower back segment can easily lead to postural instability. Our finding is in line with other literature reports of PD-related impairments in postural control of the lower back region $[13,29,30]$. Overall, poor control of the lower back region has already been reported in off-drug settings [13,30] and on-drug setting [29]. Our present study results showed that the poor control in the off-drug sessions worsens significantly in the on-drug sessions. We assume that this reflects a problematic disease-related impairment in postural control especially in the ML axis. Indeed, greater ML body sway is strongly associated with the likelihood of ML falls [31] and hip fractures [32]. Moreover, quality of life may be reduced by this impairment of the lower back region, since axial impairments are strongly associated with disability and reduced quality of life [33]. Overall, clinicians should be aware of this issue and should carefully evaluate any exaggerated ML motion of the lower back.

The present study's main objective was to test the influence of acute levodopa administration on the contributions of the two postural control mechanisms. Unexpectedly (see H2), the "on-drug" patients were able to increase the absolute contributions of their postural control mechanisms in the gaze-shift tasks, relative to the stationary gaze task (Figures 4A and 4B). Hence, the patients swayed significantly more than the controls although they were able to increase the strength of their mechanism from one task to another. In fact, our data on the relative contributions (\% $\mathrm{SD} \mathrm{COP}_{c} / \mathrm{COP}$ and $\left.\% \mathrm{SD} \mathrm{COP} / \mathrm{COP}\right)$ showed that the postural control was not more efficient in the patients than in the controls (as could have been expected on the basis of the absolute contributions); instead, the patients exerted as much strength (proportionally) as the controls ( $n s$ for patients vs. controls). As the patients swayed significantly more than the controls, they should have exhibited significantly higher relative amplitude contributions, rather than similar ones. Overall, levodopa administration significantly destabilized the patients with PD in several ways; the need to maintain balance obliged the patients to engage their postural mechanisms more than the controls did. However, despite this greater level of commitment, the patients were still not able to control their posture as well as the controls did.

In the literature on postural control, it has already been suggested that levodopa administration has neutral or even negative effects on the lower back region. For example, Burleigh et al. [7] suggested that levodopa is less effective in treating axial symptoms than distal symptoms, since levodopa changed the mean amplitude of distal muscle movement (but not proximal muscle movement) under quiet stance conditions. Furthermore, patients with PD may display axial rigidity [34] and axial kinesthesia [35]. Wright et al. [34] reported that levodopa did not significantly reduce axial rigidity. In another study, the same researchers [35] showed that levodopa significantly lowered the sensitivity threshold of the axial musculature for both the hip and the trunk. Our data were even more striking, since they showed that levodopa destabilizes postural control in stance very significantly - especially in the lower back region (Figure 3F; Table 1). Indeed, even the significantly greater use of the postural control mechanisms was not enough to prevent the patients from swaying more than the controls. In other words, the patients would have needed to elicit their postural control mechanisms even more to compensate for the destabilization caused by levodopa.

Our second main analysis probed the medication-related changes in body segment rotations. In the literature on postural control, Mancini et al. [5] found that medication did not enable patients with PD to improve their postural strategy in a functional reach test. Moreover, the patients in a study by Horak et al. [16] were unable to adapt their postural strategy and behavior to changing conditions. As expected on this basis, the patients in the present study did not modify their body segment rotations between the off-drug and on-drug 
sessions (Table 2). This result must be considered with a degree of caution because there was no difference in body segment rotations (head-on-trunk and trunk-in-space) between the controls and the patients in either session.

The present results differed from our previous results in some respects. In our earlier study [13], a group of patient with PD and a group of controls performed exactly the same three visual tasks (the stationary-gaze task and the gaze shift tasks at $0.125 \mathrm{~Hz}$ and $0.25 \mathrm{~Hz}$ ) in the off-drug condition only. The results showed that relative to the controls, the patients turned their lower back significantly more and turned their head significantly less in both tasks while we did not find the same results in the present study. In other words, the absence of significant difference for the head-on-trunk and trunk-in-space angular displacements in the present study (Table 2) was not consistent with our previous results in 2015 . Furthermore, the patients with PD barely moved their eyes in the orbit in our previous study but moved them significantly more than the controls in the present study (Table 2). There are two likely explanations for these disparities between both similar studies. Firstly, the patients were significantly stiffer off-drug in the present study (rigidity score: $8.93 \pm 4.07$ ) than in the previous one (rigidity score: $3.94 \pm 2.31 ; F(1,30)=19.19, P<0.05)$. This rigidity may have constrained them to move less their body (and therefore move their eyes in the orbit more) in the present study than in the previous study. Secondly, the patients with PD in the present study might have adopted a spontaneous eye-dominant strategy that is known to compensate for hypometric displacements of the head [12]. In our previous study, the patients could not adopt this spontaneous strategy because they were not allowed to move their eyes in the orbit (see the Methods section in [13]). Given that the patients with PD moved their eyes significantly more than the controls (by a factor of almost two; Table 2), they did not need to rotate their lower back significantly more than the controls. This may explain why we did not observe significant disease-related differences in the trunk-in-space angular displacements in the gaze-shift tasks.

Our present findings prompt two key practical messages for clinicians and patients. Firstly, levodopa administration led the patients with PD to sway more than the controls, and obliged them to commit significantly more strength of their postural control mechanisms than the controls to maintain their balance. Consequently, patients with PD may become tired more easily and more quickly in everyday life than healthy adults in performing activities that challenges their postural control - especially under on-drug conditions. Secondly, the patients were not able to compensate for the levodopa-associated destabilization, despite the greater engagement of their postural control mechanisms. Hence, patients may be more destabilized and be at a greater risk of falling when performing difficult visual tasks. Remarkably, if the patients had moved their eyes as little as the controls did, they might have moved the lower back as much as in our previous study [13]. In general, it seems that the levodopa regimen medication does not improve the postural control mechanisms enough, especially for the lower back. Hence, levodopa should be modified so that the postural control mechanisms can be better. This adjustment seems important as it could induce lower ML postural instability, and therefore lower the incidence of ML falls and related hip fractures (as there are significant links between ML postural instability, ML falls and hip fractures, [31,32]).

The present study had some limitations. One is related to the fact that the on-drug session was always performed after the off-drug session. This is a conventional procedure in the literature (see [8,11,27,30], among others), but fatigue may have acted as a confounding factor. We explained earlier why we did not believe so but we cannot exclude this possibility. Hence, our study shows a limitation of this conventional procedure and shows that it should be changed to better understand the effect of medication on postural control. In a future research, the issue in the randomization should be addressed by performing the two sessions 
on different days. We need to note that our results are still remarkable as they showed that the controls reduced their postural sway from the first to the second session while the patients with PD increased them instead ${ }^{1}$. This contrasted result should be investigated in the future. A second limitation relates to the fact that visual tasks in which a dot is tracked rightwards and leftwards for more than $30 \mathrm{sec}$ are rare in everyday life. Individuals are more used to freely exploring their visual environment either randomly or with their attention focused on specific elements (e.g. locating an object). In future research on PD-related changes in eye and body behaviors, it might be instructive to study patients with PD and controls freely exploring natural images on a large screen.

\section{Conflicts of Interest}

None

\section{Acknowledgment}

We thank the ANR LowVision for the financial support to buy the Polhemus system.

We thank visionnAIRR of the Conseil Regional Nord Pas de Calais for the financial support to pay the participants and to pay Dr David Fraser (Biotech Communication, Damery, France) for his helpful advice on the English language in this paper.

We thank Dr David Fraser (Biotech Communication, Damery, France) for his helpful advice on the English language in this paper.

We also thank France Parkinson for the financial support to pay some of the participants and the journal fees (convention $\mathrm{n}^{\circ} \mathrm{RD} 1603$ ).

\footnotetext{
${ }^{1}$ Practice or habituation could not act as a confounding factor for the patients because they did not reduce but increased their postural sway instead.
} 


\section{References}

[1] Allen NE, Schwarzel AK, Canning CG. Recurrent falls in Parkinson's disease: A systematic review. Parkinson's Disease 2013, ID 906274, http://dx.doi.org/10.1155/2013/906274.

[2] Walker RW, Chaplin A, Hancock RL, Rutherford R, Gray WK. Hip fractures in people with idiopathic Parkinson's disease: incidence and outcomes. Movement Disord.

2013;28:334-40.

[3] Nantel J, McDonald JC, Bronte-Stewart H. Effect of medication and STN-DBS on postural control in subjects with Parkinson's disease. Parkinsonism Relat D 2012;18:285e289.

[4] Nova IC, Perracini MR, Ferraz HB. Levodopa effect upon functional balance of Parkinson's disease patients. Parkinsonism Relat. D. 2004;10:411-5.

[5] Mancini M, Rocchi L, Horak FB, Chiari L. Effects of Parkinson's disease and levodopa on functional limits of stability. Clin. Biomech. 2008;23:450-8.

[6] Bronte-Stewart HM, Minn AY, Rodrigues K, Buckley EL, Nashner LM. Postural instability in idiopathic Parkinson's disease: the role of medication and unilateral pallidotomy. Brain 2002;125:2100-14.

[7] Burleigh A, Horak F, Nutt J, Frank J. Levodopa reduces muscle tone and lower extremity tremor in Parkinson's disease. Can. J. Neurol. Sci. 1995;22:280-5.

[8] Gago MF, Fernandes V, Ferreira J, Silva H, Rodrigues ML, Rocha L, Bicho E, Sousa N. The effect of Levodopa on postural stability evaluated by wearable inertial measurement units for idiopathic and vascular Parkinson's disease. Gait Posture 2015;41:459-64.

[9] Johnson L, Rodrigues J, Teo W-P, Walters S, Stell R, Thickbroom G, Mastaglia F. Interactive effects of GPI stimulation and levodopa on postural control in Parkinson's disease. Gait Posture 2015;41:929-34.

[10] Horak FB, Frank J, Nutt JG. Effects of dopamine on postural control in parkinsonian subjects: scaling set and tone. J. Neurophysiol. 1996;75:2380-96.

[11] Revilla FJ, Larsh TR, Mani A, Duker AP, Cox C, Succop P, Gartner M, Tejada CJ, Bhattacharya A. Effect of dopaminergic medication on postural sway in advanced Parkinson's disease. Frontiers Neurol. 2013; doi:10.3389/fneur.2013.00202.

[12] Anastasopoulos D, Ziavra N, Savvidou E, Bain P, Bronstein AM. Altered eye-to-foot coordination in standing Parkinsonian patients during large gaze and whole-body reorientations. Mov. Disord. 2011;26:2201-11.

[13] Bonnet CT, Delval A, Defebvre L. Parkinson's disease-related impairments in body movement, coordination and postural control mechanisms when performing $80^{\circ}$ lateral gaze shifts. IEEE Trans. Neural. Syst. Rehabil. Eng. 2015;23:849-56.

[14] Winter DA, Prince F, Stergiou P, Powell C. Medial-lateral and antero-posterior motor responses associated with center of pressure changes in quiet standing. Neurosci. Res.

Commun. 1993;12:141-8.

[15] Winter DA, Prince F, Frank JS, Powell C, Zabjek KF. Unified theory regarding AP and ML balance in quiet stance. J. neurophysiol. 1996;75:2334-43.

[16] Horak FB, Nutt JG, Nashner LM. Postural inflexibility in parkinsonian subjects. J. Neurol. Sci. 1992;11:46-58.

[17] Robichaud JA, Pfann KD, Comella CL, Corcos DM. Effect of medication on EMG patterns in individuals with Parkinson's disease. Mov. Disord. 2002;17:950-60. 
[18] Bejjani B-P, Gervais D, Arnulf I, Papadopoulos S, Demeret S, Bonnet A-M, Cornu P, Damier P, Agid Y. Axial parkinsonian symptoms can be improved: The role of levodopa and bilateral subthalamic stimulation. J. Neurol., Neurosur. Ps. 2000;68:595-600.

[19] Folstein MF, Folstein SE, McHugh PR. Mini-mental state: A practical method for grading the state of patients for the clinician. J. Psychiat. R. 1975;12:189-98.

[20] Hughes AJ, Daniel SE, Kilford L, Lees AJ. Accuracy of clinical diagnosis of idiopathic Parkinson's disease: A clinic-pathological study of 100 cases. J. Neurol. Neurosurg. Ps. 1992;55:181-4.

[21] Dimitrova D, Horak FB, Nutt JG. Postural muscle responses to multidirectional translations in patients with Parkinson's disease. J. Neurophysiol. 2004;91:489-91.

[22] McIlroy WE, Maki BE. Preferred placement of the feet during quiet stance: Development of a standardized foot placement for balance testing. Clin. Biomech. 1997;12:66-70.

[23] Bonnet CT, Cherraf S, Szaffarczyk S, Rougier P. The contribution of body weight distribution and center of pressure location in the control of mediolateral stance. J. Biomech. 2014a;47:1603-8.

[24] Bonnet CT, Cherraf S, Do M-C. Methodological requirement to analyze biomechanical postural control mechanisms with two platforms. Hum. Movement Sci. 2014b;35:94-113.

[25] Kinsella-Shaw JM, Harrison SJ, Colon-Semenza C, Turvey MT. Effects of visual environment on quiet standing by young and old adults. J. Motor Behav. 2006;38:251-64.

[26] Bonnet CT, Delval A, Defebvre L. Interest of active posturography to detect age-related and early Parkinson's disease related impairments in mediolateral postural control. J.

Neurophysiol. 2014c;412:2638-46.

[27] Baston C, Mancini M, Rocchi L, Horak F. Effects of Levodopa on Postural Strategies in Parkinson's disease. Gait Posture 2016;46:26-9.

[28] Tarantola J, Nardone A, Tacclini E, Schieppati M. Human stance stability improves with the repetition of the task: Effect of foot position and visual condition. Neurosci. Lett. 1997;228:75-8.

[29] Bridgewater KJ, Sharpe MH. Trunk muscle performance in early Parkinson's disease. Phys. Ther. 1998;78:566-76.

[30] Mancini M, Hora FB, Zampieri G, Carlson-Kuhta P, Nutt JG, Chiari L. Trunk accelerometry reveals postural instability in untreated Parkinson's disease. Parkinsonism Relat. D. 2011;17:557-62.

[31] Maki BE, Holliday PJ, Topper A.K.A. Prospective study of postural balance and risk of falling in an ambulatory and independent elderly population. J. Gerontol. 1994;49:M72-84.

[32] Rogers MW, Mille M-L. Lateral Stability and Falls in Older People. Exercise Sport Sci. R. 2003;31:182-7.

[33] Muslimovic D, Post B, Speelman JD, Schmand B, de Haan RJ. Determinants of disability and quality of life in mild to moderate Parkinson disease. Neurol. 2008;70:2241-7.

[34] Wright WG, Gurfinkel VS, Nutt J, Horak FB, Cordo PJ. Axial hypertonicity in Parkinson's disease: Direct measurements of trunk and hip torque. Exp Neurol 2007;208:3846.

[35] Wright WG, Gurfinkel VS, King LA, Nutt JG, Cordo PJ, Horak FB. Axial kinesthesia is impaired in Parkinson's disease: Effects of levodopa. Exp. Neurol. 2010;225:202-9. 